\title{
POLÍTICAS CULTURAIS NO BRASIL: PASSADO E PRESENTE
}

Antonio Albino Canelas Rubim rubim@ufba.br

A trajetória brasileira das políticas culturais produziu tristes tradições e enormes desafios. (RUBIM, 2007a) Estas tristes tradições podem ser emblematicamente sintetizadas em três palavras: ausência, autoritarismo e instabilidade.

\section{Ausências iniciais}

Por certo, com base nessas premissas teórico-conceituais não se pode pensar a inauguração das políticas culturais nacionais no Brasil Colônia, nem no Segundo Império ou mesmo na chamada República Velha (1889-1930). Tais exigências interditam que seu nascimento esteja situado no tempo colonial, caracterizado sempre pelo obscurantismo da monarquia portuguesa que perseguia as culturas 
indígena e africana e bloqueava a ocidental, através de controles rigorosos como: proibição da instalação de imprensas; censura a livros e jornais vindos de fora; interdição ao desenvolvimento da educação, em especial das universidades.

A reversão deste quadro a partir de 1808, com a fuga da família real para o Brasil, decorrente da invasão das tropas de Napoleão, não indica uma mudança. Mesmo com a Independência e com o posterior advento da República, o Estado se manteve pouco atento à cultura, que continuava a ser tratada como um privilégio e como um ornamento (COUTINHO, 2000), em uma sociedade de alta exclusão social.

\section{Inaugurações}

Os anos 30 do século XX trazem alterações políticas, econômicas e culturais, apesar das limitações do "novo" regime. Ele representa um pacto de compromisso entre os novos atores e as velhas elites agrárias. Industrialização; urbanização; manutenção do latifúndio; modernismo cultural e construção do estado nacional centralizado, política e administrativamente, são faces do "novo" país.

Nessa circunstância, desenvolve-se o campo cultural e dois experimentos quase simultâneos inauguram as políticas culturais no Brasil. Suas inscrições institucionais são distintas, mas ambos terão repercussões essenciais. Tais experimentos são: a passagem de Mário de Andrade pelo Departamento de Cultura da Prefeitura da cidade de São Paulo (1935-1938) e a implantação do Ministério da Educação e Saúde, em 1930, e mais especificamente a presença de Gustavo Capanema, à frente deste ministério no período de 1934 até 1945. 
Pode parecer surpreendente que uma experiência municipal seja reivindicada como inauguradora em um panorama histórico acerca das políticas culturais nacionais. Acontece que ela, por suas práticas e ideários, transcende em muito as fronteiras paulistanas. Sem pretender esgotar suas contribuições, pode-se afirmar que Mário de Andrade inova em: 1. Estabelecer uma intervenção estatal sistemática abrangendo diferentes áreas da cultura; 2. Pensar a cultura como algo "tão vital como o pão"; 3. Propor uma definição ampla de cultura que extrapola as belas artes, sem desconsiderá-las, e que abarca, dentre outras, as culturas populares; 4. Assumir o patrimônio não só como material; tangível e possuído pelas elites, mas também como algo imaterial, intangível e pertinente aos diferentes estratos da sociedade; 5. Patrocinar duas missões etnográficas às regiões amazônica e nordestina para pesquisar suas populações, deslocadas do eixo dinâmico do país e da sua jurisdição administrativa, mas possuidoras de significativos acervos culturais.

\section{Inaugurações autoritárias}

O movimento inaugurador foi também construído pelo ministro Gustavo Capanema, ao qual estava subordinado o setor nacional da cultura durante o governo Getúlio Vargas. Esteticamente modernista e politicamente conservador, ele continuou no ministério com a implantação da ditadura do Estado Novo em 1937. Apesar disto, acolheu muitos intelectuais e artistas progressistas, a exemplo de Carlos Drummond de Andrade, seu chefe de gabinete, Cândido Portinari, Oscar Niemeyer etc. (RAMIREZ NIETO, 2000) 
Pela primeira vez, o estado nacional realiza um conjunto de intervenções na área da cultura, que articula opressão, repressão e censura próprias de qualquer ditadura (OLIVEIRA; VELLOSO; GOMES, 1982; VELLOSO, 1987; GARCIA, 1982) com o desenvolvimento de formulações, práticas, legislações e instituições. O poderoso Departamento de Informação e Propaganda (DIP) é uma instituição singular nesta política cultural, pois conjuga como ninguém censura e iniciativa, buscando reprimir e cooptar o meio cultural, intelectuais, artistas e criadores. Assim, o governo Getúlio Vargas/Gustavo Capanema inaugurou uma atuação sistemática do estado na cultura. Dentre outros procedimentos, têm-se a criação de legislações para o cinema, a radiodifusão, as artes, as profissões culturais etc. e a constituição de inúmeros organismos culturais.

No âmbito destas organizações, cabe destacar o Serviço do Patrimônio Histórico e Artístico Nacional (SPHAN), pois ele será a instituição emblemática da política cultural no país até o final dos anos 1960 e início da década seguinte. O Serviço, depois Instituto ou Secretaria, opta pela preservação do patrimônio de pedra e cal, de cultura branca, de estética barroca e teor monumental. Em geral: igrejas católicas, fortes e palácios do período colonial. Com isto, o SPHAN circunscreve a área de atuação, dilui possíveis polêmicas, desenvolve sua competência técnica qualificada e profissionaliza seu pessoal. Tais atitudes, em conjunto com seu "insulamento institucional", irão garantir a independência e a impressionante continuidade organizacional e administrativa da entidade e de seu dirigente. (MICELI, 2001, p. 362) Elas transformam o SPHAN em algo exemplar para as políticas culturais no Brasil e em muitos outros países. Sua força é também sua fraqueza. A opção elitista e a não interação com as comunidades interessadas nos sítios preservados impediram o SPHAN de acompanhar desenvolvimentos na área de patrimônio e o colocaram como alvo de severas críticas. (MICELI, 2001; GONÇALVES, 1996) 
A gestão inauguradora de Vargas/Capanema cria uma outra e difícil tradição no país: a forte relação entre governos autoritários e políticas culturais nacionais que irá marcar de modo substantivo a história brasileira. A política cultural implantada valorizava o nacionalismo, a brasilidade, a harmonia entre as classes sociais, o trabalho e o caráter mestiço do povo brasileiro.

\section{Paradoxais ausências}

O interregno democrático de 1945 a 1964 reafirma as duas tristes tradições. O esplendoroso desenvolvimento da cultura brasileira que acontece no período, em quase todas suas áreas, não tem correspondência com o que ocorre nas políticas culturais nacionais. Elas, com exceção da atuação do SPHAN, praticamente inexistem. Apenas intervenções pontuais marcam o período democrático. A instalação do Ministério da Educação e Cultura, em 1953; a expansão das universidades públicas (nacionais); a Campanha de Defesa do Folclore e a criação do Instituto Superior de Estudos Brasileiros, órgão vinculado ao MEC.

A atuação de outras instituições, em geral não estatais, deve ser recordada por suas repercussões na área cultural e no estado. Os Centros Populares de Cultura (CPC) da União Nacional dos Estudantes, instalados no Rio de Janeiro (1961) e em outras cidades agitam a juventude, em especial universitária, ainda que com vida curta, pois serão fechados em 1964, juntamente com o Instituto Superior de Estudos Brasileiros (ISEB). (BERLINK, 1984; BARCELLOS, 1994) Entretanto, a avaliação dos CPCsC e sua relação com a chamada cultura nacional-popular, que marca aquele momento histórico e mesmo os anos imediatos pós-golpe militar (1964-1968), é bastante polêmica. Outra intervenção a do 
Movimento de Cultura Popular, desencadeado pelos governos municipal e estadual de Miguel Arraes, no qual aparece a notável figura de Paulo Freire com seu método pedagógico que conjuga educação e cultura. (SCHELLING, 1991) O movimento se expandiu para outros estados e foi bloqueado pelo Golpe de 1964.

\section{Autoritarismo militar}

A ditadura reafirmou a triste tradição do vínculo entre políticas culturais e autoritarismo. Os militares reprimiram, censuraram, perseguiram, prenderam, assassinaram, exilaram intelectuais, artistas, cientistas e criadores populares, mas, ao mesmo tempo, constituíram uma agenda de "realizações" nada desprezível para a (re)configuração da cultura no Brasil.

De 1964 até 1968, apesar da repressão e da censura, ainda não sistemática, acontecem manifestações políticas contra o regime, em especial dos setores médios, e existe todo um movimento cultural, uma espécie de floração tardia dos anos anteriores, hegemonicamente de esquerda, mas com audiência circunscrita às classes médias, como assinalou Roberto Schwarz (1978). Além da violência, a ditadura age estimulando a passagem da predominância de circuito cultural escolar-universitário para um dominado por uma dinâmica de cultura midiatizada. (RUBIM; RUBIM, 2004) Com este objetivo, a instalação da infraestrutura de telecomunicações; a criação de empresas e a implantação de uma lógica de indústria cultural são realizações dos governos militares, que controlam rigidamente os meios audiovisuais e buscam integrar simbolicamente o país, de acordo com a política de "segurança nacional". 
O segundo momento (final de 1968 - 1974), o mais brutal da ditadura, é dominado pela violência, prisões, tortura, assassinatos e censura sistemática bloqueando toda a dinâmica cultural anterior. Época de vazio cultural contrariado apenas pela cultura "marginal”. Tempo de imposição crescente de uma cultura midiática, tecnicamente sofisticada e fiel reprodutora da ideologia oficial.

Com a relativa derrota da ditadura nas eleições legislativas de 1974, abre-se o terceiro momento que termina com o final do regime militar no início de 1985 . Tal período se caracteriza pela "distensão lenta e gradual" (General Geisel) e pela "abertura" (General Figueiredo). Isto é, por uma longa transição cheia de avanços e recuos. A violência diminui e o regime passa a ter iniciativas político-culturais. A tradição da relação entre autoritarismo e políticas culturais é retoma em toda sua amplitude. O regime para realizar a transição sob sua hegemonia busca cooptar os profissionais da cultura (ORTIZ, 1985, p. 85), inclusive através da ampliação de investimentos na área. Pela primeira vez o país terá um Plano Nacional de Cultura (1975) e inúmeras instituições culturais são criadas. (MICELI, 1984) Destaque especial para dois movimentos acontecidos neste rico período de políticas culturais. Primeiro: a criação e o desenvolvimento da FUNARTE, outra das instituições emblemáticas de políticas culturais no Brasil, a partir da experiência do Plano de Ação Cultural de 1973. (BOTELHO, 2001a) Segundo, as mutações organizacionais, de pensamento e de ação associados à figura de Aloísio Magalhães. Em sua rápida trajetória nestes anos, facilitada por seu dinamismo, criatividade e relações com alguns setores militares, Aloísio criou ou alterou organismos culturais até sua morte prematura em 1982. Sua visão renovada ensejou uma mudança nas antigas concepções de patrimônio vigentes no país, ainda que com limitações, devido à persistência de alguns traços comuns como a "retórica da perda". 
(GONÇALVES, 1996) Por certo que tais movimentos não conviveram sem tensões internas e, inclusive, entre eles, e com muitos problemas. (ORTIZ, 1985; BOTELHO, 2001a)

\section{Instabilidades}

A conjugação de ausência e autoritarismo produz instabilidade, a terceira triste tradição. Ela tem, de imediato, uma faceta institucional. Muitas das entidades culturais criadas têm forte instabilidade institucional derivada de um complexo conjunto de fatores: fragilidade; ausência de políticas mais permanentes; descontinuidades administrativas; desleixo; agressões de situações autoritárias etc.

O fim da ditadura praticamente torna inevitável a criação do Ministério da Cultura. O setor de cultura esteve inscrito no Ministério de Educação e Saúde (1930) até passar a compor o Ministério de Educação e Cultura, em 1953. Foram precisos mais 32 anos para a independência e autonomia da cultura em um ministério singular (1985) e sua implementação foi deveras complicada. A sua implantação é um exemplo contundente desta tradição de instabilidade: criado em 1985 por Sarney; desmantelado por Collor e transformado em secretaria em 1990; novamente recriado em 1993 por Itamar Franco. Além disto, foram dez dirigentes responsáveis pelos órgãos nacionais de cultura em dez anos (1985-1994): cinco ministros nos cinco anos de Sarney; dois secretários no período Collor e três ministros no governo Itamar Franco. A permanência média de um dirigente por ano cria uma considerável instabilidade institucional para um organismo que está em processo de instalação.

A instabilidade não decorre tão somente da mudança quase anual dos responsáveis pela cultura. Collor, no primeiro e tumultuado 
experimento neoliberal no país, praticamente desmonta a área de cultura no plano federal. Acaba com o ministério, reduz a cultura a uma secretaria e extingue inúmeros órgãos. Mas as ambiguidades não provinham somente destes aspectos. Em 1986, foi criada a chamada lei Sarney, primeira lei brasileira de incentivos fiscais para financiar a cultura. (SARNEY, 2000) A lei foi concebida em um movimento aparentemente paradoxal, pois o governo simultaneamente estava inaugurando o ministério e diversos órgãos. A lei terminava por contrariar este investimento, pois introduzia uma ruptura radical com os modos de financiar a cultura. $\mathrm{O}$ estado reduzia o financiamento direto e propunha que as verbas fossem buscadas no mercado. Só que este dinheiro em boa medida era público, decorrente do mecanismo de renúncia fiscal. Apesar disto, o poder de decisão era privatizado.

A lógica das leis de incentivo torna-se componente vital do financiamento à cultura no Brasil. Esta nova lógica de financiamento se expandiu para estados e municípios e para outras leis nacionais, a exemplo da Lei do Audiovisual (Governo Itamar Franco), que ampliou ainda mais a renúncia fiscal. Com ela e com as posteriores mudanças da lei Rouanet, ${ }^{1}$ cada vez mais o recurso utilizado é quase integralmente público. A predominância desta lógica de financiamento corrói o poder de intervenção do Estado nas políticas culturais e potencializa a intervenção do mercado, sem, entretanto, a contrapartida do uso de recursos privados.

A cruel combinação entre escassez de recursos estatais e a afinidade desta lógica de financiamento com os ideários neoliberais então vivenciados no mundo e no país, fez que parcela considerável dos criadores e produtores culturais passasse a identificar política de financiamento e, pior, políticas culturais tão somente com as leis de incentivo. Outra vez a articulação entre democracia e políticas culturais se mostrava problemática. O Estado persistia em sua ausência no campo cultural em tempos de democracia. 


\section{Novas ausências}

No governo Fernando Henrique Cardoso (FHC)/Francisco Weffort, esta nova modalidade de ausência atinge seu ponto culminante. José Castello (2002), avaliando o governo FHC, afirma uma quase identidade entre Estado e mercado; fala das leis de incentivo como sendo a política cultural e diz que as leis de incentivo escamoteiam a ausência de uma política cultural. Em verdade e em boa medida, as leis de incentivo foram entronizadas como a política cultural.

Esta ausência na era FHC vem confirmar a incapacidade da democracia no Brasil de atuar na área da cultura, detectada por um dos principais mentores do Ministério da Cultura naquele governo, o professor José Álvaro Moisés, que havia reconhecido outra das tristes tradições brasileiras: a íntima relação entre cultura e autoritarismo no país.

O novo governo caracteriza-se pela implantação, de modo menos tosco e mais enfático, do projeto neoliberal no Brasil. A retração do Estado acontece em praticamente todas as áreas, substituído pelo mercado. Aliás, se houve política de cultura, ela se concentrou em ampliar a utilização das leis de incentivo pelo mercado. A utilização de dinheiro público subordinado a decisão privada se ampliou bastante. Um estudo sobre financiamento da cultura mostrou que o uso de recursos sofreu profunda transformação entre 1995, 66\% das empresas e 34\% de renúncia fiscal, e 2000, $35 \%$ das empresas e $65 \%$ de renúncia fiscal. (DÓRIA, 2003, p. 101) Em outras palavras, as leis de incentivo ao investimento privado em cultura estavam desestimulando tal atitude, pois o dinheiro cada vez mais era público.

As críticas a esta política de retirada do Estado da decisão sobre as políticas de cultura são muitas e diversas (SARKOVAS, 2005; 
OLIVIERI, 2004; CASTELLO, 2002): 1. O poder de deliberação de políticas culturais passa do Estado para as empresas e seus departamentos de marketing; 2. Uso quase exclusivo de recursos públicos; 3. Ausência de contrapartidas; 4. Incapacidade de alavancar recursos privados novos; 5 . Concentração de recursos. Em 1995, por exemplo, metade dos recursos (mais ou menos 50 milhões) estava em apenas 10 programas; 6 . Projetos voltados para institutos criados pelas próprias empresas; 7. Apoio equivocado à cultura mercantil que tem retorno comercial; 8 . Concentração regional dos recursos.

Assim, com exceção de algumas políticas setoriais, como a de bibliotecas e patrimônio (Projeto Monumenta) e a legislação acerca do patrimônio imaterial, o longo período de oito anos de estabilidade da direção do Ministério da Cultura, contraposto ao quadro anterior de instabilidade, pouco colaborou para consolidação institucional do Ministério. O orçamento destinado à cultura no último ano do governo Fernando Henrique Cardoso/Francisco Weffort sintetiza de modo sintomático a falta de importância do Ministério e a ausência de uma política cultural ativa. Ele foi de apenas $0,14 \%$ do orçamento nacional.

\section{Enfrentamentos}

Esboçada esta digressão histórica, é possível analisar como o Governo Lula/Gil tem enfrentado ou não tais desafios. Outra vez, a ausência pode ser o ponto de partida. Na coletânea dos discursos "programáticos" pronunciados em seu primeiro ano de governo, Gilberto Gil privilegiou dois temas que batiam de frente com a tradição da ausência. Ele enfatizou o papel ativo do estado e fez críticas contundentes à gestão FHC/Weffort (GIL, 2003, p. 23, $49,50,51,52,53)$. 
O papel ativo do estado tem se concretizado em inúmeras áreas culturais. Aliás, o próprio Gil disse que a marca de sua gestão seria a abrangência. $O$ papel ativo do estado se fez em conexão com a sociedade. Ele, várias vezes, afirmou que o público do ministério não eram apenas os criadores e produtores culturais, mas a sociedade brasileira. Deste modo, o diálogo com a sociedade deu substância ao caráter ativo, abrindo veredas para enfrentar outro desafio: o autoritarismo. Ou seja, o essencial desafio de formular e implementar políticas culturais em circunstâncias democráticas foi nitidamente colocado na agenda do ministério.

Outra das ênfases dos discursos programáticos confronta o autoritarismo e o elitismo: a ampliação do conceito de cultura. A adoção da noção "antropológica" permite que o ministério deixe de estar circunscrito à cultura erudita e abra suas fronteiras para outras culturas: populares; afro-brasileiras; indígenas; de gênero; de orientações sexuais; das periferias; da mídia áudio-visual; das redes informáticas etc.

Em alguns casos, a atuação do Ministério da Cultura passa mesmo a ser inauguradora, a exemplo da atenção e do apoio às culturas indígenas. (BRASIL, 2006, p. 26) Em outros revela um diferencial de investimento em relação às situações anteriores. É o que acontece nas culturas populares. (BRASIL, 2005), de afirmação sexual, na cultura digital e mesmo na cultura midiática audiovisual. A abertura conceitual e de atuação significa não só o abandono de uma visão elitista e discriminadora de cultura, mas representa um contraponto ao autoritarismo e a busca da democratização das políticas culturais. A intensa opção por construir políticas públicas, porque em debate com a sociedade, emerge como outra marca da gestão Gil. Assim, proliferam os seminários; as câmaras setoriais; as conferências, inclusive culminando na Conferência Nacional de Cultura. 
As políticas públicas dão substrato democrático para a viabilização de políticas de Estado, que transcendendo governos, possam viabilizar políticas nacionais mais permanentes. Nesta perspectiva, os investimentos, ainda iniciais, do ministério na área da economia da cultura e da economia criativa e sua ação junto ao IBGE no sentido de produzir séries de informações culturais adquirem notável funcionalidade e já apresentam seus primeiros resultados. (IBGE, 2006) Mas dois outros movimentos assumem lugar central na construção de políticas de Estado no campo cultural: a implantação e desenvolvimento do Sistema Nacional de Cultura (SNC) e do Plano Nacional de Cultura (PNC).

A construção que vem sendo realizada pelo ministério, em parceria com estados, municípios e sociedade civil, de um SNC é vital para a consolidação de estruturas e de políticas, pactuadas e complementares, que viabilizem a existência de programas culturais de médios e longos prazos, não submetidas às intempéries conjunturais. Tal sistema deve estar associado e comportar outros (sub)sistemas como o Sistema Nacional de Museus. (BRASIL, 2006, p. 22) A aprovação pelo Congresso Nacional (Emenda Constitucional $n^{\circ} 48 / 2005$ ) e subsequente elaboração do PNC surge como outro fator favorável à superação da tradição de instabilidade. Enfim, a possibilidade de superação desta triste tradição depende em ampla medida da existência, articulação e sintonia fina entre SNC e PNC.

A institucionalização do ministério se consolida com sua atuação cada vez mais nacional, através de inúmeros projetos, com destaque para os Pontos de Cultura. A descentralização das atividades do ministério decorre também da reforma administrativa realizada logo no início da gestão, que buscou superar as áreas de sombreamento e dar maior operacionalidade ao ministério e seus órgãos vinculados. (MEIRA, 2004) A realização do "primeiro concurso 
público da história do ministério" desde que foi criado há mais de vinte anos (BRASIL, 2006, p. 18), traz perspectivas alvissareiras para o fortalecimento institucional do ministério, através da incorporação de novos servidores.

Dois outros fatores têm essencial significado para a construção institucional do ministério. O primeiro é a ampliação do orçamento do ministério, ainda que isto não tenha atendido à meta dos ministros Gilberto Gil e Juca Ferreira, de um por cento para o orçamento nacional de cultura. $\mathrm{O}$ segundo é a permanência do mesmo projeto, no segundo mandato do presidente Lula. Esta manutenção pode ser interpretada como compromisso com a continuidade das políticas empreendidas.

\section{Limitações e desafios}

Um dos aspectos mais positivos na avaliação da gestão do Ministério da Cultura é a abrangência assumida como meta. Esta amplitude representa um enorme desafio de continuidade e de articulação das infindáveis veredas trilhadas. Dar contemporaneidade ao ministério exige consolidação e acolhimento de novos horizontes. A continuidade torna-se crucial para a maioria dos projetos em andamento e, em especial, para alguns que têm indiscutível centralidade: o SNC; o PNC; o Sistema Nacional de Informações Culturais; a tessitura de uma nova política nacional de financiamento da cultura, que recoloque o estado em seu lugar; os pontos de cultura; o equacionamento do tema das culturas audiovisual e digital; a consolidação institucional e política do ministério etc.

Para atingir tais objetivos, entretanto, alguns limitações e obstáculos têm que ser enfrentados. Um esforço conceitual e teórico se 
faz necessário para delimitar com mais rigor o campo de atuação do ministério. O conceito antropológico se acerta ao reconhecer que todo indivíduo produz cultura, cria problemas quando abraça como cultura tudo que não é natureza. Isaura Botelho já anotou a dificuldade desta "definição alargada" para a efetiva formulação de políticas culturais e para o próprio delineamento institucional do ministério. (BOTELHO, 2001b)

Os interessantes canais de participação da sociedade civil e dos artistas precisam ser avaliados e consolidados, inclusive institucionalmente. Nesta perspectiva, encontros, seminários, conferências assumem lugar de destaque.

A concentração dos equipamentos, que persiste apesar da nacionalização das atividades do ministério, continua a ser um grave problema, porque ela age ativamente contra esta distribuição mais equitativa de recursos humanos, materiais e financeiros, com repercussões inevitáveis e indesejáveis na democratização da cultura. Apesar do imenso simbolismo da realização do primeiro concurso público para o ministério, continua acentuada a necessidade de quadros para as instituições culturais nacionais. A carência de pessoal e sua má distribuição tornam-se ainda mais graves, devido à ausência de políticas de valorização salarial e de formação, qualificação e atualização. A instituição de um sistema nacional de formação e qualificação em cultura, inserido dentro do SNC, pode ser uma possível alternativa a esta grave omissão.

Outro enfrentamento vital e inevitável: a questão do financiamento da cultura. Desde a perversa instalação das leis de incentivo, que contaminaram toda a arquitetura institucional da cultura, existem enormes problemas neste registro. As leis de incentivo parecem esgotar o tema das políticas de financiamento, quando não das próprias políticas culturais. Apesar dos avanços inegáveis, com a 
instituição de uma política de editais para a cultura no ministério (Fundo Nacional de Cultura) e em empresas estatais, o tema ainda demanda um grande esforço para superar a lógica neoliberal que entronizou o mercado como o poder de decisão acerca da cultura brasileira. A ausência de uma política de financiamento corrói as iniciativas do ministério, inclusive aquela primordial de fazer o Estado assumir um papel mais ativo na cultura.

A conquista do mínimo de um por cento do orçamento para a cultura e o aumento dos recursos para a área devem estar associados à construção institucional de uma política de financiamento, submetida à política pública e nacional de cultura.

Enfim, o desafio a ser enfrentado pode ser condensado na construção de uma política de Estado - nacional e pública - de cultura, consubstanciada em um documento, que represente a superação democrática das tristes tradições detectadas. A democracia brasileira está a exigir para a sua consolidação a ampliação dos direitos culturais e da cidadania cultural em nosso país.

\section{Notas}

${ }^{1}$ No governo Collor, a Lei Sarney foi extinta e substituída por outra lei de incentivo fiscal, a Lei ${ }^{\circ} 8.313 / 91$, que leva o nome do segundo Secretário de Cultura dessa gestão, Sérgio Paulo Rouanet.

\section{Referências}

ABDANUR, Elizabeth França. Os 'Ilustrados'e a política cultural em São Paulo: o Departamento de Cultura na Gestão Mário de Andrade (1935-1938). 1992. 187f. Dissertação (Mestrado em História) - UNICAMP, Campinas, 1992. BADARÓ, Murilo. Gustavo Capanema: a revolução na cultura. Rio de Janeiro: Nova Fronteira, 2000. 
BARBALHO, Alexandre. Relações entre Estado e cultura no Brasil. Ijuí: Editora UNIJUÍ, 1998.

BARBATO JÚNIOR, Roberto. Missionários de uma utopia nacional-popular: os intelectuais e o Departamento de Cultura de São Paulo. São Paulo: Annablume: Fapesp, 2004.

BARCELLOS, Jalusa. CPC-UNE: uma história de paixão e consciência. Rio de Janeiro: Nova Fronteira, 1994.

BASTOS, Mônica Rugai. O espelho da nação: a cultura como objeto de política no governo Fernando Henrique Cardoso. 2004. 324f. Tese (Doutorado em Sociologia) - Faculdade de Filosofia e Ciências Humanas, Universidade de São Paulo, São Paulo, 2004.

BERLINK, Manoel T. Centro Popular de Cultura da UNE. Campinas, SP: Papirus, 1984.

BOTELHO, Isaura. Romance de formação: FUNARTE e política cultural 1976-1990. Rio de Janeiro: Casa de Rui Barbosa, 2001a.

. Dimensões da cultura e políticas públicas. São Paulo em Perspectiva.

v. 15, n. 2, 2001b, p. 73-83.

BRASIL. Ministério da Cultura. Cultura é um bom negócio. Brasília, 1995.

. Seminário Nacional de Políticas Públicas para as Culturas Populares.

Brasília, 2005.

. Programa cultural para o desenvolvimento do Brasil. Brasília, 2006.

BUCHBINDER, Pablo. Historia de las universidades argentinas. Buenos Aires: Editorial Sudamerica, 2005.

CASTELLO, José. Cultura. In: LAMOUNIER, Bolívar; FIGUEIREDO, Rubens (Org.) A Era FHC: um balanço. São Paulo: Cultura, 2002. p. 627-656.

CHAGAS, Mário. O pai de Macunaíma e o patrimônio espiritual. In: ABREU, Regina; CHAGAS, Mário (Org.). Memória e patrimônio: ensaios contemporâneos. Rio de Janeiro: FAPERJ/DP\&A/UNI-RIO, 2003, p. 95-108.

CHAUÍ, Marilena. Brasil: mito fundador e sociedade autoritária. São Paulo: Fundação Perseu Abramo, 2000.

. O nacional e o popular na cultura brasileira: seminários. São Paulo:

Brasiliense, 1983.

COUTINHO, Carlos Nelson. Cultura e sociedade na Brasil. Rio de Janeiro: DP\&A, 2000.

DEMO, Pedro. Dimensão cultural da política social. Recife: Massangana, 1982. 
DÓRIA, Carlos Alberto. Os federais da cultura. São Paulo: Biruta, 2003.

FERNANDES, Florestan. A revolução burguesa no Brasil. Rio de Janeiro: Zahar, 1975.

FERREIRA, Juca. Ancinav: "omissão ou missão"? Revista Teoria e Debate, São Paulo, n. 60, p. 64-67, nov./dez. 2004.

FUNDAÇÃO JOÃO PINHEIRO. A indústria cultural no quadro da economia brasileira. Brasília: MINC, 1987.

GARCIA, Nelson Jahr. Estado Novo: ideologia e propaganda política.

São Paulo: Loyola, 1982.

GIL, Gilberto. Discursos do Ministro da Cultura Gilberto Gil. Brasília: Ministério da Cultura, 2003.

GOMES, Ângela de Castro (Org.). Capanema: o ministro e o ministério. Rio de Janeiro: Fundação Getúlio Vargas, 2000.

GONÇALVES, José Reginaldo Santos. A retórica da perda: os discursos do patrimônio cultural no Brasil. Rio de Janeiro: Editora da UFRJ: IPHAN, 1996.

IBGE - INSTITUTO BRASILEIRO DE GEOGRAFIA E ESTATÍSTICA. Sistema de informações e indicadores culturais 2003. Rio de Janeiro, 2006.

MAGALHÃES, Aloísio. E Triunfo? A questão dos bens culturais no Brasil. Rio de Janeiro: Nova Fronteira; Brasília: Fundação Nacional Pró-Memória, 1985.

MEIRA, Márcio. Uma política republicana. Revista Teoria e Debate. São Paulo, n. 58 , p. $60-65$, maio/jun. 2004.

MICELI, Sérgio (Org.) Estado e cultura no Brasil. São Paulo: Difel, 1984. . Intelectuais à brasileira. São Paulo: Companhia das Letras, 2001.

MOISÉS, José Álvaro. Estrutura institucional do setor cultural no Brasil. In: MOISÉS, José Álvaro et al. Cultura e democracia. Rio de Janeiro: Edições Fundo Nacional de Cultura, 2001. p. 13-55. (v. 1)

NUSSBAUMER, Gisele Marchiori (Org.) Teorias e políticas da cultura: visões multidisciplinares. Salvador: EDUFBA, 2007.

OLIVEIRA, Lúcia Lippi; VELLOSO, Mônica Pimenta; GOMES, Ângela de Castro. Estado Novo: ideologia e poder. Rio de Janeiro: Zahar Editores, 1982.

OLIVIERI, Cristiane Garcia. Cultura neoliberal: leis de incentivo como política pública de cultura. São Paulo: Escrituras/Instituto Pensarte, 2004.

ORTIZ, Renato. A moderna tradição brasileira: cultura brasileira e indústria cultural. São Paulo: Brasiliense, 1989. . Cultura brasileira e identidade nacional. São Paulo: Brasiliense, 1985. 
PARTIDO DOS TRABALHADORES. A imaginação a Serviço do Brasil. Caderno de Campanha. São Paulo, 2002.

PARTIDO DOS TRABALHADORES. Brasil: cultivar a memória, inventar o futuro. Programa Setorial de Cultura. São Paulo, 2006.

PONTES, Ipojuca. Cultura e modernidade. Brasília: Secretaria de Cultura, 1991.

RAFFAINI, Patrícia Tavares. Esculpindo a cultura na forma Brasil: o Departamento de Cultura de São Paulo (1935-1938). 1999. 126f. Dissertação (Mestrado em História) - Faculdade de Filosofia, Letras e Ciências Humanas, Universidade de São Paulo. São Paulo, 2001.

RAMÍREZ NIETO, Jorge. El discurso Vargas Capanema y la arquitectura moderna en Brasil. Bogotá: Universidad Nacional de Colômbia, 2000.

RUBIM, Antonio Albino Canelas. Políticas culturais no Brasil: tristes tradições, enormes desafios. In: RUBIM, Antonio Albino Canelas Rubim; BARBALHO, Alexandre. Políticas Culturais no Brasil. Salvador: EDUFBA, 2007a, p. 11-36.

. Políticas culturais entre o possível e o impossível. In:

NUSSBAUMER, Gisele Marchiori (Org.) Teorias e políticas da cultura: visões multidisciplinares. Salvador: EDUFBA, 2007b, p. 139-158.

. Políticas culturais e o Governo Lula. São Paulo: Editora da Fundação

Perseu Abramo, 2011.

. Cultura e políticas culturais. Rio de Janeiro: Azougue, 2011.

. (Org.) Políticas culturais no Governo Lula. Salvador, EDUFBA, 2010.

; RUBIM, Lindinalva. Televisão e políticas culturais no Brasil. Revista USP, São Paulo, n. 61, p. 16-29, 2004.

SARKOVAS, Yacoff. O incentivo fiscal no Brasil. Revista Teoria e Debate.

São Paulo, nº. 62, p. 58-62, abr./maio 2005.

SARNEY, José. Incentivo à cultura e sociedade industrial. In: JELÍN, Elizabeth e outros. Cultura e desenvolvimento. Rio de Janeiro: Fundo Nacional de Cultura, 2000. p. 27-44.

SCHELLING, Vivian. A presença do povo na cultura brasileira. Ensaio sobre o pensamento de Mário de Andrade e Paulo Freire. Campinas, SP: Editora da UNICAMP, 1991.

SCHWARZ, Roberto. Cultura e política: 1964-1969. In: família e outros estudos. Rio de Janeiro: Paz e Terra, 1978. p. 61-92.

SOUZA, Márcio. Fascínio e repulsa: Estado, cultura e sociedade no Brasil. Rio de Janeiro: Edições Fundo Nacional de Cultura, 2000. (Cadernos de Nosso Tempo; 2) 
TOLEDO, Caio Navarro de. ISEB: fábrica de ideologias. São Paulo: Ática, 1977.

VELLOSO, Mônica Pimenta. Os intelectuais e a política cultural do Estado Novo. Rio de Janeiro: Centro de Pesquisa e Documentação de História Contemporânea do Brasil - Fundação Getúlio Vargas, 1987.

WILLIAMS, Daryle. Gustavo Capanema. Ministro da Cultura. In: GOMES, Ângela de Castro (Org.) Capanema: o ministro e seu ministério. Rio de Janeiro: Editora FGV, 2000. p. 251-269. 